\title{
Guillaume de Berneville, La Vie de saint Gilles
}

\section{Barbara Ferrari}

\section{OpenEdition}

\section{Journals}

Édition électronique

URL : https://journals.openedition.org/studifrancesi/38968

DOI : 10.4000/studifrancesi.38968

ISSN : 2421-5856

\section{Éditeur}

Rosenberg \& Sellier

\section{Édition imprimée}

Date de publication : 1 décembre 2004

Pagination : 335

ISSN : 0039-2944

\section{Référence électronique}

Barbara Ferrari, «Guillaume de Berneville, La Vie de saint Gilles », Studi Francesi [En ligne], 143 (XLVIII |

II) | 2004, mis en ligne le 30 novembre 2015, consulté le 19 mai 2021. URL : http://

journals.openedition.org/studifrancesi/38968; DOI : https://doi.org/10.4000/studifrancesi.38968

Ce document a été généré automatiquement le 19 mai 2021.

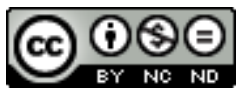

Studi Francesi è distribuita con Licenza Creative Commons Attribuzione - Non commerciale - Non opere derivate 4.0 Internazionale. 


\title{
Guillaume de Berneville, La Vie de saint Gilles
}

\author{
Barbara Ferrari
}

\section{RÉFÉRENCE}

GUILLAUME DE BERNEVILLE, La Vie de saint Gilles, édition bilingue traduite, présentée et annotée par FRANÇOISE LAURENT, Paris, Champion (Champion Classiques "Moyen Age", 6), 2003, pp. 309.

1 Dans son ouvrage Plaire et édifier. Les récits hagiographiques composés en Angleterre au XII et XIII siècle (Paris, Champion 1998), F.L. consacrait une centaine de pages à l'analyse de la Vie de saint Gilles de Guillaume de Berneville (vers 1170), texte dont "l'intérêt narratif et religieux" justifiait, à son avis, "une étude particulière" (p. 475). Elle nous donne ici une nouvelle édition de ce texte, plus d'un siècle après celle de Gaston Paris et Alphonse Bos (S.A.T.F. 1881). Même si F.L. reconnaît sa dette à l'égard de ses devanciers (cfr. Avant-propos, p. IX), son édition ne se présente pas comme une simple reprise: le texte établi par Paris et Bos a en effet été revu et corrigé sur le microfilm du ms. Florence, Bibl. Laurenziana n. 99 Conventi Soppressi, le seul à conserver la totalité du poème; en outre l'attitude adoptée par F.L. dans l'établissement du texte (conformément à la pratique ecdotique actuelle) est plus conservative que celle des anciens éditeurs, qui n'avaient pas hésité à intervenir dans le cas de "fautes" contre la déclinaison ou de hiatus.

2 Dans la riche introduction (pp. XI-LXIV) F.L. décrit la tradition manuscrite de la Vie, s'arrête sur le problème de l'identification de l'auteur, présente la source latine de l'oeuvre, et, après avoir passé en revue les différentes positions critiques concernant la réalité historique de saint Gilles, en suit les vicissitudes en tant que personnage littéraire. L'analyse plus proprement littéraire du poème reprend en partie les observations formulées dans les pp. 475-576 du volume Plaire et Edifier cité ci-dessus. Même si F.L. déclare ne pas avoir voulu présenter une étude systématique de la langue 
du ms. de Florence, les remarques linguistiques qui complètent l'introduction rendent compte amplement des phénomènes graphiques, phonologiques et morphologiques, ainsi que des caractéristiques de la versification du poème (pp. LVI-LXIV).

3 Le texte (pp. 1-235), avec traduction en français moderne en regard, est accompagné de notes philologiques, linguistiques et historiques, tandis que l'apparat critique est placé à la fin du poème (pp. 237-241). Suit un dossier qui présente le texte-source latin, avec traduction en regard, et la transcription du fragment du ms. Londres, B. L., Harl. 912, correspondant aux vv. 2974-3057 du texte français (signalé par Louis Brandin dans la "Romania" en 1904). L'édition est complétée par un index des noms propres (pp. 277-282), qui ne figurait pas dans Paris-Bos, et par un glossaire sélectif mais qui comprend les mots appartenant à un vocabulaire spécialisé (religion, chasse, navigation etc.: pp. 283-299). 